\title{
Microstructure development in Laser Metal Deposition of Ti-5553
}

\author{
C. Hicks ${ }^{\mathrm{a}, \mathrm{b}, *}$, T. Konkova ${ }^{\mathrm{b}}$, P. Blackwell ${ }^{\mathrm{b}}$ \\ ${ }^{a}$ Advanced Forming Research Centre (AFRC), University of Strathclyde, 85 Inchinnan Drive, Glasgow, UK \\ besign, Manufacturing \& Engineering Management (DMEM) Department, University of Strathclyde, 75 \\ Montrose Street, Glasgow, UK \\ *calum.hicks@strath.ac.uk
}

\begin{abstract}
$\underline{\text { Abstract }}$
Laser Metal Deposition (LMD) is promoting increased interest with regard to manufacturing parts of complex geometry. It is especially important with respect to manufacturing cost reductions for relatively expensive Titanium alloys. The rapid and directional cooling processes inherent with LMD produce nonhomogeneous microstructures and large residual stresses. Knowledge of the LMD process to optimise deposited microstructures is in high demand. The high-strength $\beta$-Titanium alloy, Ti-5Al-5Mo-5V-3Cr (Ti5553), was deposited using LMD on to a heat-treated substrate of the same alloy. Two blocks of $15 \times 15 \mathrm{x}$ $6.4 \mathrm{~mm}^{3}$ were made with different laser power to powder feed rate ratios followed by microstructural analyses. Both blocks have almost identical geometry and density. Low ratios of laser power to powder feed rate resulted in pure $\beta$ phase in the deposited layers and the re-melted material in the substrate. High ratios resulted in larger columnar $\beta$ grains, the precipitation of nano-scaled $\alpha$, and a pronounced increase in microhardness $\approx 1 \mathrm{~mm}$ above and below the substrate interface. This could be detrimental to the mechanical properties of the substrate and highlights the importance of the optimisation of LMD parameters.
\end{abstract}

\section{Introduction}

Additive manufacturing (AM) is an emerging technology that is able to produce near-net shape components with lower buy-to-fly ratios compared to traditional machining [1]. Laser Metal Deposition (LMD) is one such technology that is gaining particular interest within the aerospace industry. It is capable of adding features to large forgings and repairing surface defects and cracks [1-3]. LMD is particularly attractive for use with expensive alloys such as those based on Titanium, where minimisation of material waste, tool wear and manufacturing lead-time can be improved [1].

Material deposited with LMD is often plagued by porosity, large residual stresses, and highly anisotropic microstructures [3-6]. These can be reduced through using high quality powder feedstock and optimised process parameters [4-9]. To this end, extensive research of LMD has been conducted in recent years to improve understanding of the process.

The widely used alloy, Ti-6Al-4V, has seen the bulk of attention, with research on the effect of process parameters such as laser power and powder feed rate, and their associated effect on the mechanical properties, density, microstructure and residual stress of deposited components [4-7]. However, there is scope for greater understanding of the deposited microstructure of high-strength $\beta$-Ti alloys such as Ti-5Al$5 \mathrm{Mo}-5 \mathrm{~V}-3 \mathrm{Cr}$ (Ti-5553), which are used in undercarriage applications for commercial aircraft such as in the Boeing $787[10]$.

The limited literature data on the LMD of Ti-5553 (and the similar Ti-5Al-5Mo-5V-1Cr-1Fe alloy) demonstrate that the as-deposited microstructure is characterised by large columnar $\beta$ grains and limited $\alpha$ precipitation $[8,11,12]$. The latter is generally improved with higher laser powers; however, this can coarsen the $\beta$ grain structure [12], and could increase the heat affected zone within the substrate material, all of which can be detrimental to mechanical performance. It is also unclear the effect the process parameters have at the substrate interface, which is of high importance when adding features to larger forgings. To this end, a comparison of the microstructure of deposited layers and the substrate interface of LMD Ti-5553 under low and high laser power to powder feed rate ratios will allow a greater understanding of optimised deposition process parameters. 


\section{Experimental}

Ti-5553 was used as the workpiece material in this research. A forged Ti-5553 billet was initially subjected to $\beta$ annealing at $100^{\circ} \mathrm{C}$ above the $\beta$-transus for $3 \mathrm{hrs}$ in a vacuum furnace, followed by air cooling at $10^{\circ} \mathrm{C}$ per minute to room temperature. In addition, an ageing treatment was conducted at $810^{\circ} \mathrm{C}$ for $2 \mathrm{hrs}$ followed by a water quench. The substrate material was extracted from a forged billet.

Blocks of Ti-5553 were deposited on the Ti-5553 substrate by LMD with a $2 \mathrm{~kW}$ TRUMPF disc laser by Laser Additive Solutions Ltd. The powder feedstock was atomised by AP\&C using a plasma atomisation process and subsequently sieved into a particle size distribution of 45-106 $\mu \mathrm{m}$. Each block was of dimensions $15 \times 15 \mathrm{~mm}^{2}$ in the normal direction (ND) and transverse direction (TD), and consisted of 16 layers incrementally spaced by $0.4 \mathrm{~mm}$ (z-increment) along the build direction (BD). The spacing between scan track centrelines within each layer is $0.8 \mathrm{~mm}$. Scanning pattern was linear tracks aligned in the same direction, upon which each layer rotates the pattern by $90^{\circ}$ as illustrated in Figure 1. Localised argon shielding has been used. Scanning speed is $600 \mathrm{~mm} / \mathrm{min}$.

Layer 1

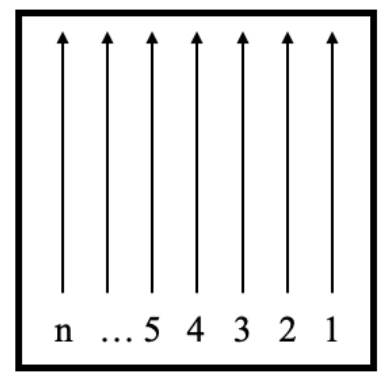

Layer 3

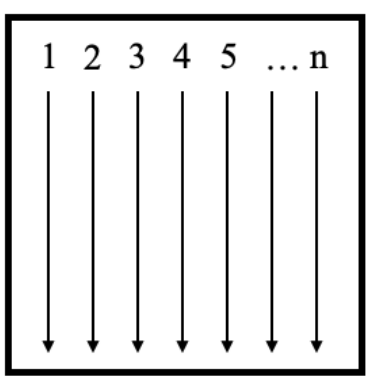

Layer 2

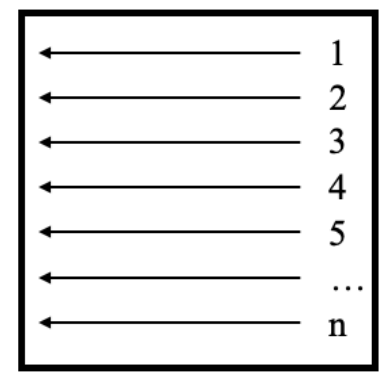

Layer 4



Figure 1 - Scanning pattern of deposition.

The deposition height of $6.4 \mathrm{~mm}$ is expected; however, this requires a good ratio between the laser power and powder feed rate. The process parameters used for both specimens are summarised in Table 1.

Density measurements were completed using the Archimedes method with a Mettler Toledo balance and density measurement kit. Measurements were repeated a minimum of four times for repeatability.

For microstructural examination by optical microscopy, the blocks were sectioned both parallel and perpendicular to the build direction, i.e. in BD-ND and ND-TD planes. Standard techniques of metallographic preparation were applied, i.e. grinding and polishing followed by etching with Kroll's reagent, washing with methanol and drying with an air flow. For scanning electron microscopy (SEM), samples were subjected to electro-polishing in an electrolyte consisting of methanol, 2-butoxyethanol and perchloric acid, at $40 \mathrm{~V}$ for $30 \mathrm{~s}$ followed by washing with methanol and drying with an air flow. SEM imaging and electron back scatter diffraction (EBSD) analysis was obtained using a Thermo Fisher Scientific Quanta 250 SEM and an Oxford Instruments EBSD camera, with a $20 \mathrm{kV}$ accelerating voltage and a $4.5 \mathrm{~mm}$ spot size. EBSD maps were created with a $5 \mu \mathrm{m}$ step size and achieved a minimum indexed proportion of $80 \%$ or greater for all scans. Noise reduction has been applied through standard "clean-up" procedure to replace non-indexed pixels with orientations based on their neighbouring pixels. 
EBSD post-processing has been completed in AZtecHKL software by Oxford Instruments. Grains were characterised as areas surrounded by high-angle boundaries. A $15^{\circ}$ criterion was applied to differentiate lowangle boundaries (LABs) from high-angle boundaries (HABs).

Vickers microhardness distribution testing was conducted on a DuraScan 70 G5 hardness tester for a load of $1 \mathrm{~kg}$ (HV1) for $10 \mathrm{~s}$. The spacing between indents was $0.75 \mathrm{~mm}$. Post-processing of data has been completed in MATLAB.

\section{$\underline{\text { Results }}$}

Two blocks demonstrated minimal deviation from the expected height and geometry: a low laser power specimen (LP) and a high laser power specimen (HP), which were $3 \%$ and $1 \%$ overbuilt respectively (Table 1). Both LP and HP displayed high densities of $99.3 \%$ and $99.6 \%$ of the substrate material respectively, which had an absolute density of $4.59 \mathrm{~g} / \mathrm{cm}^{3}$. The highly dense material is reflected in all microstructural analyses, in which no apparent voids or areas of poor fusion are visible.

Table 1 - AM process parameters and resulting height deviation of LMD Ti-5553 blocks.

\begin{tabular}{|l||l||l||l||}
\hline Specimen & $\begin{array}{l}\text { Laser Power, } \\
\mathrm{W}\end{array}$ & $\begin{array}{l}\text { Powder feed rate, } \\
\mathrm{g} / \mathrm{min}\end{array}$ & $\begin{array}{l}\text { Height deviation from } \\
\text { expected }\end{array}$ \\
\hline $\mathrm{LP}$ & 550 & 1.8 & $3 \%$ overbuilt \\
\hline HP & 650 & 1.4 & $1 \%$ overbuilt \\
\hline
\end{tabular}

\section{Microstructure}

The microstructure transition from the substrate into the deposited layers of specimen LP and HP is shown in Figure $2 \mathrm{a}$, and $\mathrm{b}$. The substrate material is characterised by the presence of large equiaxed $\beta$ grains of an average size of $470 \mu \mathrm{m}$, and a homogeneous dispersion of fine micro-scaled $\alpha$ laths that decorate the grain boundaries $(\mathrm{GB} \alpha)$ and interiors as seen in Figure $2 \mathrm{~d}$. 


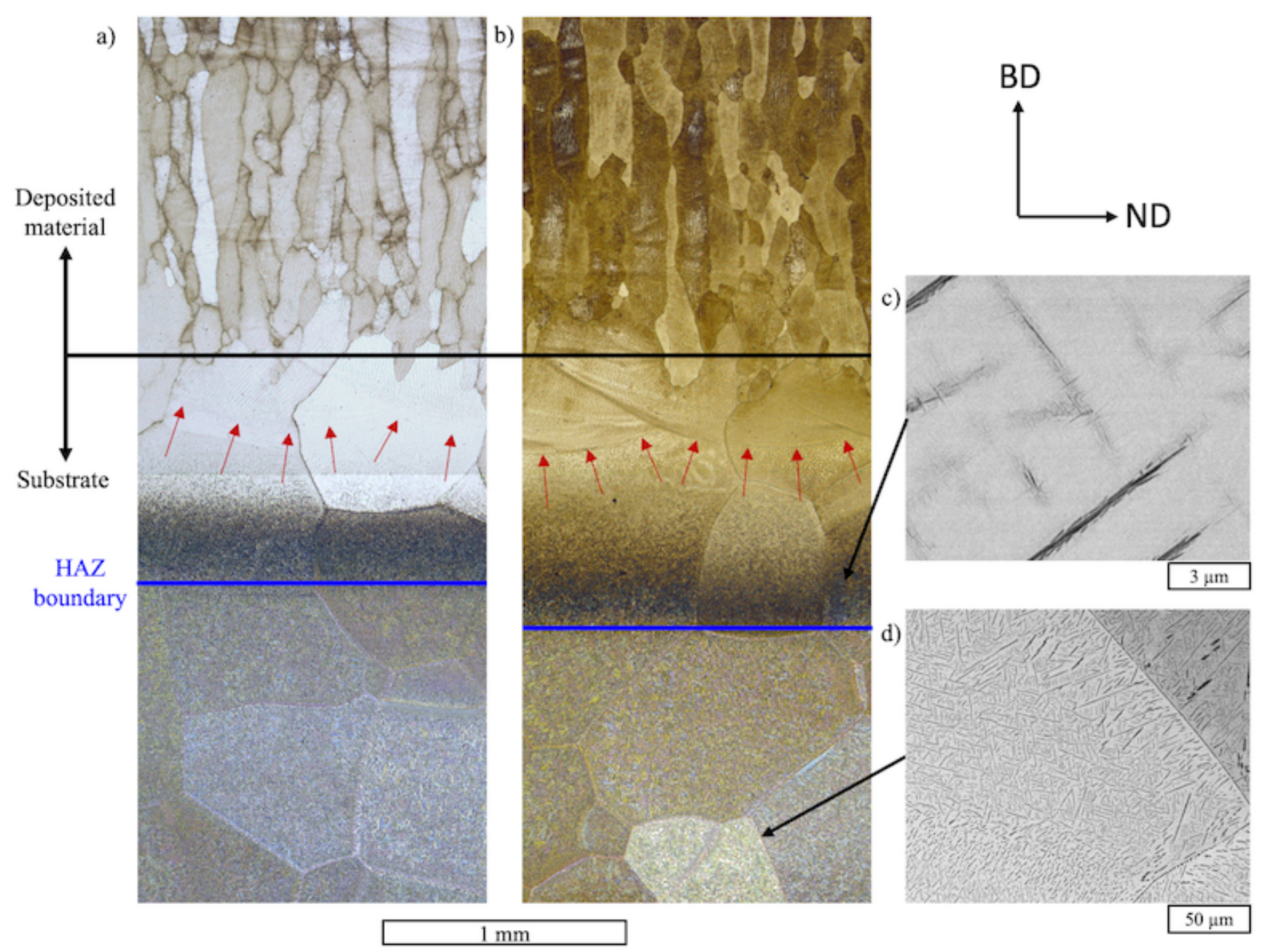

Figure 2 - The transition from the substrate to the deposited layers in the LP (a) and HP (b) specimen. Red arrows indicate re-melted materials (c): Magnified image of HAZ showing microscaled $\alpha$ dissolution. (d): Magnified image of typical substrate microstructure.

In contrast, deposited material is characterized by large columnar $\beta$ grains, often several millimetres in length, aligned in the build direction. Most likely, epitaxial grain growth took place, and grains have grown through multiple deposited layers. Specimen LP has smaller $\beta$ grains than specimen HP as outlined in Table 2 , however within each specimen the aspect ratios in the BD-ND and ND-TD planes was comparable.

Table 2 - Average $\beta$ grain size and aspect ratios within centre of deposited material. Sizing calculated from EBSD maps.

\begin{tabular}{|l||l||l||l||}
\hline $\begin{array}{l}\text { Analysis } \\
\text { plane }\end{array}$ & Specimen & $\begin{array}{l}\text { Average } \beta \text { grain size, } \\
\mu \mathrm{m}\end{array}$ & $\begin{array}{l}\text { Average grain aspect } \\
\text { ratio }\end{array}$ \\
\hline BD-ND & LP & 103.2 & 2.9 \\
\hline \hline & HP & 134.8 & 3.0 \\
\hline ND-TD & LP & 84.5 & 1.5 \\
\hline \hline & HP & 114.4 & 1.6 \\
\hline
\end{tabular}

The substrate interface region was characterised with several notable features as annotated in Figure 2a and b. Columnar grains initiated in freshly deposited material immediately above the substrate interface. The remelted substrate material maintains the typical large equiaxed $\beta$ grain morphology. 
The heat affected zone (HAZ) is located below the re-melted substrate material (Figure 2a and b), where the $\beta$ grain morphology remains unaffected, but displays dissolution of the substrate's micro-scaled $\alpha$ phase, as shown in Figure 2c. In specimen LP and HP, the re-melted material extended on average $305 \mu \mathrm{m}$ and 366 $\mu \mathrm{m}$ respectively into the substrate, whilst the HAZ extended roughly $910 \mu \mathrm{m}$ and $1090 \mu \mathrm{m}$ respectively.

Deposited material in the LP specimen is generally characterised by pure $\beta$ phase, with little to no nanoscaled $\alpha$ precipitating even on grain boundaries as indicated with an arrow in Figure 3a. Conversely, specimen HP displays significant nano-scaled $\alpha$, both along grain boundaries and within grains (Figure $3 b$ ).

At the substrate interface of specimen LP, a marginal amount of $\alpha$ has precipitated along grain boundaries; however, this is not consistent as indicated by the arrow in Figure 3c, which shows a grain boundary triple point with incomplete grain boundary $\alpha$. In contrast, specimen HP displays nano-scaled $\alpha$ along grain boundaries and interiors (Figure 3d). A similar $\alpha$ morphology is found within the re-melted material of the substrate (Figure 3e and f).

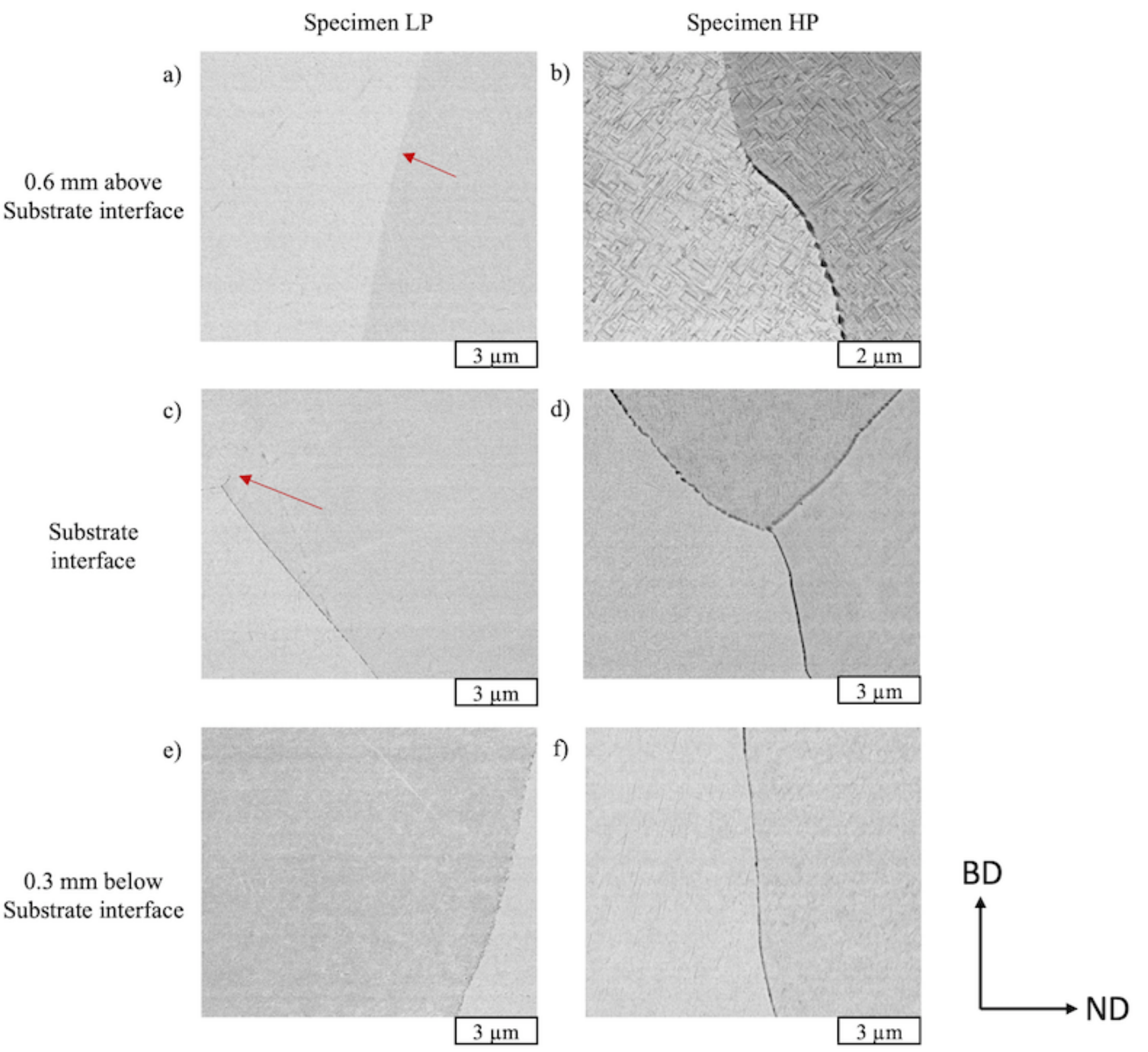

Figure 3 - SEM BSE images of specimen LP (a, c, e) and specimen HP (b, d, f) at various locations. (a and $b): 0.6 \mathrm{~mm}$ above the substrate interface within the second deposited layer. (c and d): at the substrate interface. (e and $\mathrm{f}$ ): $\mathbf{0 . 3} \mathrm{mm}$ below the substrate interface within the re-melted material. 
The microhardness plots for specimen LP and HP, and their associated mapped locations are shown in Figure 4. Unaffected substrate material has a hardness of $\approx 310 \mathrm{HV}$. A fairly uniform microhardness distribution was observed in the LP sample, with a maximum of approximately $320 \mathrm{HV}$ around $1 \mathrm{~mm}$ below the substrate interface. The deposited layers display slightly lower microhardness than the substrate at $300 \mathrm{HV}$. Specimen HP is characterised by higher microhardness around the substrate interface: surpassing $390 \mathrm{HV}$. The increased microhardness is suspected to be an outcome of the nano-scaled $\alpha$ precipitates.

\section{Discussion}

\section{Beta-grain morphology}

As previously mentioned, the $\beta$ grain morphology within the re-melted material of the substrate would appear to reflect that grain growth took place based on the pre-existing grain orientations i.e. epitaxial grain growth occurred.

Above the substrate interface, the columnar growth morphology dominated. The smaller $\beta$ grains of specimen LP are thought to be due to a greater number of incomplete melted powder particles that can act as nucleation points for $\beta$ grains. This is in line with research by Wang et al. who found that increasing the powder feed rate promoted more equiaxed grains at the top of the melt-pool of LMD Ti-6-4 [13].

b)

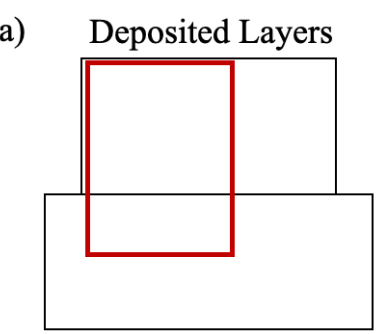

Substrate

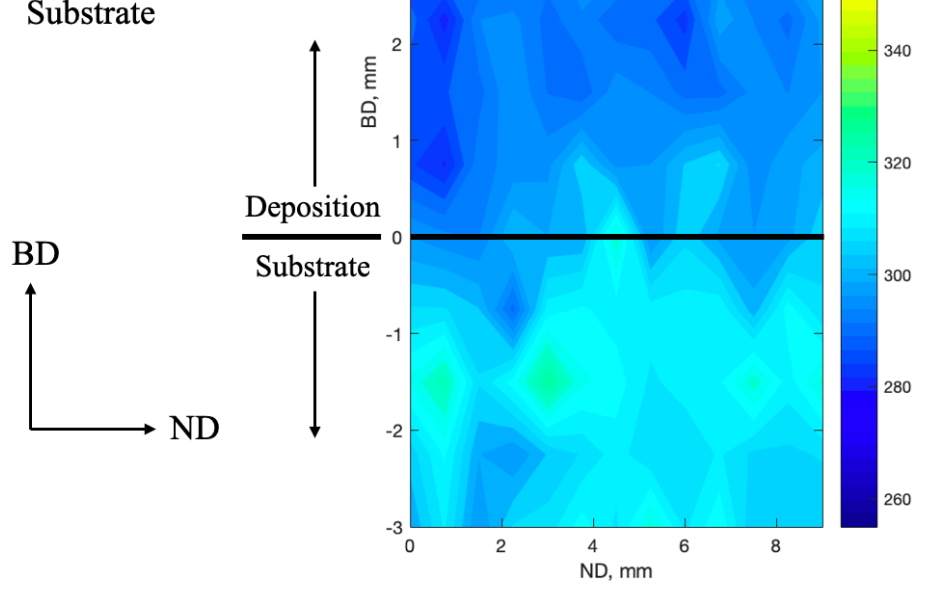

c)

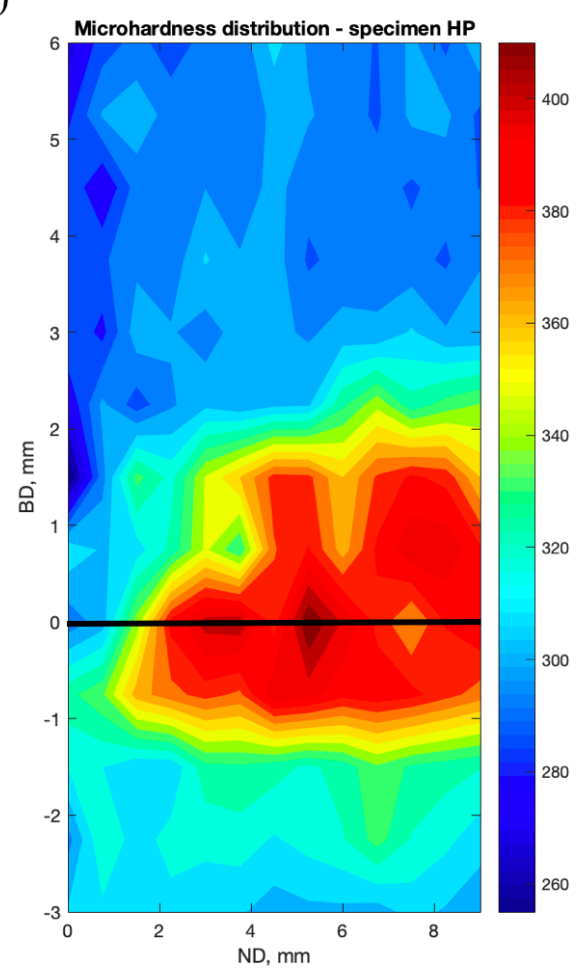

Figure 4 - Vickers microhardness mapping areas for specimen LP and HP (a), and the associated distributions for specimen LP (b) and specimen HP (c).

\section{Nano-scaled $\alpha$ precipitates}

The microhardness of specimen HP is thought to be noticeably higher around the substrate interface due to the precipitation of the nano-scaled $\alpha$ visible in Figure $3 b, d$ and $f$. The heat flux from the melt-pool conducts rapidly through previously deposited layers to diffuse into the substrate. The deposition of subsequent layers produces additional heat fluxes that allow precipitation of $\alpha$ around the substrate interface and lower layers. The additional laser power of specimen HP has provided additional heat to precipitate significantly more $\alpha$ than specimen LP. This appears to have had a direct effect on the microhardness, not just within the deposited layers, but also within the substrate material. The microhardness of this area is similar to as-forged levels [14], and it is expected that the strength will be similarly high. 
Phase-boundary strengthening is the main method of strengthening $\beta$ alloys [15]. It is clear that the distribution of fine $\alpha$ laths around the substrate interface have dramatically increased the amount of $\alpha / \beta$ phase boundaries, which consequently restricts the movement of dislocations. However, microstructures consisting of sub-micron $\alpha$ often fail in a brittle manner as there is no ductile phase within the microstructure to accommodate plastic deformation [14]. This is undesirable in many engineering applications; and, considering that this area extends over $1 \mathrm{~mm}$ into the substrate, highlights the importance of LMD process parameter optimisation.

The mechanism for the nano-scaled $\alpha$ precipitation is unclear in this case; however, it is hypothesised that $\omega$ assisted nucleation has occurred. He et al. [16], demonstrated in laser surface re-melted Ti-55511 that athermal $\omega$ phase is present in the re-melted zone. Subsequent ageing at $500^{\circ} \mathrm{C}$ precipitated nano-scaled $\alpha$. After 10 mins of ageing the microhardness had reached above $420 \mathrm{HV}$ which is comparable to the HP specimen in this study. Considering that the LMD blocks took $\approx 13$ minutes to be built, it is feasible that the $\alpha$ has precipitated via the same mechanism.

\section{Conclusion}

Ti-5553 has been deposited with two different laser power to powder feed rate ratios, that both produce highly dense builds of equal heights. The low ratio specimen consisted of smaller $\beta$ grains in the deposited material and an almost pure $\beta$ phase microstructure in both the deposited layers and HAZ. Conversely, the high ratio specimen produced larger $\beta$ grains, and precipitated nano-scaled $\alpha$ within the lower deposited layers and the HAZ. This dramatically increased the microhardness of this area. The precipitation of the nano-scaled $\alpha$ is thought to be facilitated by the greater heat flux of the higher laser power.

The precipitation of $\alpha$ within the HAZ makes it clear that process parameters need to be optimised to avoid detrimental effects on the microstructure of the substrate for feature addition and component repair applications.

\section{$\underline{\text { Acknowledgements }}$}

The authors would like to acknowledge the support provided by the Advanced Forming Research Centre (AFRC), University of Strathclyde, which receives partial financial support from the UK's High Value Manufacturing CATAPULT.

\section{References}

[1] B. Dutta, F.H. (Sam) Froes, The Additive Manufacturing (AM) of titanium alloys, Met. Powder Rep. 72 (2017) 96-106. doi:10.1016/j.mprp.2016.12.062.

[2] S. Ford, M. Despeisse, Additive manufacturing and sustainability: an exploratory study of the advantages and challenges, J. Clean. Prod. 137 (2016) 1573-1587. doi:10.1016/j.jclepro.2016.04.150.

[3] D.D. Gu, W. Meiners, K. Wissenbach, R. Poprawe, Laser additive manufacturing of metallic components: materials, processes and mechanisms, Int. Mater. Rev. 57 (2012) 133-164. doi:10.1179/1743280411Y.0000000014.

[4] B.A. Szost, S. Terzi, F. Martina, D. Boisselier, A. Prytuliak, T. Pirling, M. Hofmann, D.J. Jarvis, A comparative study of additive manufacturing techniques: Residual stress and microstructural analysis of CLAD and WAAM printed Ti-6Al-4V components, Mater. Des. 89 (2016) 559-567. doi:10.1016/j.matdes.2015.09.115.

[5] W. Zhang, A. De, A. Wilson-Heid, A.M. Beese, J.W. Elmer, J.S. Zuback, T. Mukherjee, J.O. Milewski, T. DebRoy, H.L. Wei, Additive manufacturing of metallic components - Process, structure and properties, Prog. Mater. Sci. 92 (2017) 112-224. doi:10.1016/j.pmatsci.2017.10.001.

[6] B.E. Carroll, T.A. Palmer, A.M. Beese, Anisotropic tensile behavior of Ti-6Al-4V components fabricated with directed energy deposition additive manufacturing, Acta Mater. 87 (2015) 309-320. doi:10.1016/j.actamat.2014.12.054.

[7] X. Wu, J. Liang, J. Mei, C. Mitchell, P.S. Goodwin, W. Voice, Microstructures of laser-deposited Ti6Al-4V, Mater. Des. 25 (2004) 137-144. doi:10.1016/j.matdes.2003.09.009.

[8] A. Hatefi, Direct Laser Fabrication of Ti-5553, University of Birmingham, 2013. http://etheses.bham.ac.uk/4667/2/Hatefi13MRes.pdf (accessed November 9, 2017).

[9] M.N. Ahsan, A.J. Pinkerton, R.J. Moat, J. Shackleton, A comparative study of laser direct metal 
deposition characteristics using gas and plasma-atomized Ti-6Al-4V powders, Mater. Sci. Eng. A. 528 (2011) 7648-7657. doi:10.1016/j.msea.2011.06.074.

[10] P. Singh, H. Pungotra, N.S. Kalsi, On the characteristics of titanium alloys for the aircraft applications, Mater. Today Proc. 4 (2017) 8971-8982. doi:10.1016/j.matpr.2017.07.249.

[11] C.M. Liu, H.M. Wang, X.J. Tian, H.B. Tang, D. Liu, Microstructure and tensile properties of laser melting deposited Ti-5Al-5Mo-5V-1Cr-1Fe near $\beta$ titanium alloy, Mater. Sci. Eng. A. 586 (2013) 323-329. doi:10.1016/j.msea.2013.08.032.

[12] C. Qiu, G.A. Ravi, M.M. Attallah, Microstructural control during direct laser deposition of a $\beta$ titanium alloy, Mater. Des. 81 (2015) 21-30. doi:10.1016/j.matdes.2015.05.031.

[13] T. Wang, Y.Y. Zhu, S.Q. Zhang, H.B. Tang, H.M. Wang, Grain morphology evolution behavior of titanium alloy components during laser melting deposition additive manufacturing, J. Alloys Compd. 632 (2015) 505-513. doi:10.1016/j.jallcom.2015.01.256.

[14] R. Panza-Gios, The Effect of Heat Treatment on the Microstructure Evolution and Mechanical Properties of Ti-5Al-5V-5Mo-3Cr, and Its Potential Application in Landing Gears., McMaster University, 2009.

[15] G. Lütjering, J.C. Williams, Titanium, Ed. SPRINGER. second edi (2007) 1-442. doi:10.1007/978-3540-73036-1.

[16] B. He, X. Cheng, J. Li, G.C. Li, H.M. Wang, $\omega$-assisted $\alpha$ phase and hardness of Ti-5Al-5Mo-5V-1Cr$1 \mathrm{Fe}$ during low temperature isothermal heat treatment after laser surface remelting, J. Alloys Compd. 708 (2017) 1054-1062. doi:10.1016/j.jallcom.2017.03.089. 